\title{
DOSSIE UM SEMEADOR DA ANTROPOLOGIA OS ANTROPÓLOGOS COMO NATIVOS E SEUS RITOS
}

João Pacheco de Oliveira

Desde o seu livro de estréia, O processo de assimilação dos Terena, publicado em 1960 pelo Museu Nacional, até Caminhos da identidade: ensaios sobre etnicidade e multiculturalismo, editado pela UNESP em 2006, Roberto Cardoso de Oliveira nos deixa uma obra extensa e preciosa, única na antropologia brasileira. Foram 46 anos de intensa atividade intelectual, da qual resultaram muitas dezenas de livros, artigos e ensaios que marcaram época e foram decisivos para instituir pontos de inflexão na prática da disciplina.

Foi o principal responsável por uma nova abordagem às sociedades indígenas, um olhar que se expressou em uma narrativa inteiramente original, respaldada por uma problemática teórica da qual se ocupou de forma rica e consistente em diferentes pesquisas de campo (Terena, Tukuna, México e Espanha). Em muitos textos analíticos veio a recuperar tais experiências, estabelecendo um profícuo diálogo intelectual com antropólogos que produziam a partir de outros contextos institucionais e etnográficos, em um esforço comparativo e de tradução cultural sempre articulado com os desafios do exercício de um trabalho teórico. Nas duas últimas décadas, sua atenção dirigiu-se com surpreendente vigor para questões de interesse metateórico na antropologia. Em sucessivos ensaios e conferências, depois transformados em livros, veio a ocupar-se de temas como os paradigmas e a história da disciplina, a escrita etnográfica e o trabalho de campo, e as relações entre a ética e a antropologia.

Meu objetivo aqui, neste pequeno texto que integra um conjunto de artigos publicados na revista Mana em homenagem aos fundadores do PPGAS/ Museu Nacional, não é de maneira alguma empreender uma leitura de sua obra, que continua muito viva e atual e prescinde, portanto, de um exercício de intermediação. O que pretendo focalizar não é o autor Roberto Cardoso de Oliveira (ou RCO, como de forma resumida e neutra costumava referir-se a si mesmo em notas ou comentários ao longo dos textos), mas um personagem que teve presença muito forte, em certos momentos até determinante, na vida da comunidade de antropólogos que vivem ou atuam no Brasil. 
Ao debruçar-me sobre memórias e narrativas, a minha intenção é buscar traduzir para o domínio do vivido alguns aspectos e momentos de convívio com esse personagem. São apenas fragmentos, pinceladas que não têm qualquer pretensão sistematizadora, nem expressam mais que uma visão pessoal. Mas talvez, na escala dos pequenos episódios e na linguagem do testemunho - terreno bem familiar aos antropólogos - possam fornecer para as gerações mais novas algumas "pistas" sobre o impacto desse personagem sobre os seus contemporâneos.

O primeiro ponto a salientar é a sua preocupação, sempre reiterada, com as condições de formação do antropólogo. Ao tratar do ensino e da prática da antropologia, Roberto (como gostava de ser chamado por seus alunos e colegas mais próximos, num esforço em distinguir-se do autor RCO) sempre se situava de um ponto de vista duplamente sociológico, isto é, como alguém que descreve e analisa um conjunto de fenômenos sociais que pode ser objetivado através da investigação empírica e do exercício do debate e da crítica, na continuidade da dimensão argumentativa. A produção do antropólogo e do pesquisador social é em si mesma um fato social, devendo ser descrita e analisada em termos de valores e interesses de grupos e instituições.

Nunca alimentou auto-representações e construções fortemente idealizadas na história das ciências, na qual uma abstrata dupla de papéis - o mestre e o discípulo - desenraizada de outras mediações sociais, funciona como um artifício encantatório, substituindo uma compreensão mais ampla de todo o processo. A formação do antropólogo, que exige condições concretas (recursos humanos, espaço físico e instalações, bibliotecas e sistemas de intercâmbio e divulgação científica), é fruto de uma instituição social articulada a uma rede de instituições congêneres, não devendo ser reduzida a pares dicotômicos nem descrita de forma atomizada.

A meu ver, reside justamente nessa sua visão uma das razões básicas para o seu elevado grau de compromisso e de investimento institucional. Roberto não foi tão somente alguém que contribuiu para o avanço da teoria e da pesquisa antropológica, mas sim um verdadeiro semeador de nichos institucionais para a produção de especialistas e o desenvolvimento da antropologia. No início de sua carreira, atuando juntamente com Darcy Ribeiro e Eduardo Galvão, ainda no âmbito das atividades do antigo Museu do Índio e como colaborador do SPI (Serviço de Proteção aos Índios), Roberto já se empenhava na formação de antropólogos.

Na segunda metade dos anos 60, ele conseguiu implantar um curso de especialização em antropologia já no espaço acadêmico do Museu Nacional, estabelecendo uma fecunda conexão com Luiz de Castro Faria e com David Maybury-Lewis, e o projeto de estudo sobre o Brasil Central da Universidade 
de Harvard. Foi nesse contexto institucional que surgiu, em 1968, simultaneamente com a pós-graduação criada na Universidade de São Paulo (USP), o curso de mestrado oferecido pelo Programa de Pós-Graduação em Antropologia Social (PPGAS), como uma alternativa pioneira de formação específica e profissionalizante em antropologia.

Alguns anos depois, em 1972, tendo como colaboradores alguns de seus ex-alunos (notoriamente Roque de Barros Laraia, Julio Cezar Melatti e Alcida Ramos) e o apoio financeiro da Fundação Ford, Roberto veio a criar na capital federal, dentro de um espaço universitário (a UNB), um novo programa de mestrado em antropologia, que coordenou durante vários anos.

Consolidados os mestrados do Museu Nacional e da UNB, ambos com finalidades e estruturas muito semelhantes, Roberto empenhou-se em duas experiências universitárias novas. Uma, na Universidade de Campinas, iniciou-se na segunda metade dos anos 80, estando voltada para uma formação mais ampla em ciências humanas, implicando a articulação da antropologia com outras disciplinas no âmbito da formação de pós-graduandos e das atividades de pesquisa. Nos anos 90, já como professor aposentado, ele retornou à UNB, vindo a desempenhar um papel decisivo na consolidação de um programa de formação de estudantes pós-graduados da América Latina. No CEPPAC (Centro de Estudos e Pesquisas para América Latina e Caribe), Roberto continuou a desenvolver intensa atividade, ministrando seminários, orientando teses e coordenando pesquisas, até o seu súbito falecimento.

Cabe observar ainda que o seu impacto sobre a consolidação da pósgraduação em antropologia no Brasil não se limitou apenas às instituições em que esteve presente durante períodos prolongados. Sua atuação em inúmeros conselhos e comissões do CNPq e da CAPES foram fundamentais para que a antropologia tivesse seu espaço estabelecido no plano da formulação das políticas oficiais para o fomento das atividades científicas e de educação. Sua presença em conselhos de agências de fomento, como a FINEP, foram importantes para assegurar critérios e orientações científicas, bem como para viabilizar programas de pesquisa e projetos institucionais que foram centrais na consolidação da antropologia no país. Sua participação em conselhos de outras instituições, como o Museu Paraense Emílio Goeldi e a Fundação Joaquim Nabuco, foi também de relevo.

Na sua visão, não se deveria jamais imaginar o ensino distanciado da pesquisa. Uma marca da atuação de Roberto foi sempre a sua permanente preocupação em fortalecer e estimular a pesquisa antropológica. É através do exercício do ofício de etnógrafo que a formação do antropólogo se completa, permitindo dominar métodos e teorias e aplicando-os à produção de conhecimentos novos. É por isso que sua presença nas instituições onde 
atuou sempre trouxe a dinâmica da formação de equipes de pesquisa, a articulação interinstitucional, a configuração de novos objetos e linhas de investigação. Mesmo o trabalho teórico junto com as atividades de reflexão e escrita integravam-se a um processo mais amplo e coletivo, envolvendo a preparação de cursos e seminários, a pesquisa de campo (apresentada e debatida), o exercício da crítica e do diálogo intelectual.

Em sala de aula, como professor, Roberto era uma figura fascinante. Definia os temas e as bibliografias com extremo cuidado, sempre preocupado em selecionar um conjunto de textos que pudesse informar ao estudante os desdobramentos importantes da pesquisa em antropologia e nas ciências humanas. Cada leitura proposta tinha esta função, a de abrir uma gaveta e apontar para um universo novo de investigação, fosse com indígenas, com camponeses, em contextos urbanos, no Brasil, nos Andes, na Índia, na América do Norte.

Não bastava, porém, que a seleção de textos e autores realizada nos seminários contivesse boas e inspiradoras leituras; era essencial que de algum modo refletisse a diversidade de enquadramentos analíticos e posicionamentos em face do tema debatido. Sem isso, achava, não surgia a tensão e a fagulha criativa capazes de propiciar novos insights e formulações. Em um momento em que o discurso científico se colocava como monolítico e autoritário, apontando para um saber acumulado, universal e progressivo, Roberto sempre se colocava de maneira pluralista. E não apenas em seus textos, mas na sua prática como professor, na identificação das potencialidades de escolas, problemáticas e tradições intelectuais.

Os seminários funcionavam como estruturas muito abertas, sem a imposição de uma linha rígida de apreensão nem a imposição de uma exegese específica de cada texto. O modelo era talvez uma livre assembléia de espíritos estimulados por um conjunto comum de leituras. Os estudantes participavam quando formavam opinião, comunicando-as aos demais, justificando-as ou reformulando-as. Era nesse embate que Roberto via a sua função e se empolgava, não só buscando interpretar os textos, mas propondo sínteses e colocando-as em discussão. A preocupação com a valorização do pluralismo não implicava jamais um relativismo exacerbado, descompromissado com a construção de conhecimentos positivos e a definição de instrumentos analíticos mais adequados. Nessa atividade crítica e argumentativa, no oferecimento de interpretações, pistas e hipóteses, residia a vivacidade e o encanto desses seminários.

Um depoimento pessoal pode ajudar a dimensionar esse imenso carisma de Roberto como professor. Ainda na década de 70, quando fazia o mestrado na Universidade de Brasília, durante uma aula do curso de História 
da Antropologia, surgiu uma discussão que me pareceu muito estranha. O professor, que era Julio Cezar Melatti, havia falado sobre o L' Année Sociologique e sua importância na consolidação de uma escola de pensamento. Possivelmente estimulados pelo lançamento do Anuário Antropológico, alguns estudantes fizeram comentários aproximando as duas iniciativas. Inesperadamente alguém associou Roberto Cardoso a Durkheim. Ao invés de o assunto morrer, a comparação pareceu motivar os demais, o que talvez fosse só um deslize transformando-se em assunto de reflexão, até o momento em que um dos participantes fulminou: "A analogia devia ser com Marcel Mauss, não com Durkheim!" Consenso estabelecido, voltou-se à discussão da sociologia francesa, para evidente alívio do professor, preocupado com o uso inadequado da comparação pelos neófitos da disciplina.

Nos anos seguintes, ouvi de colegas que a mesma associação fora feita em outras turmas. Rimos muito da engraçada coincidência desse non sense, que aparentemente viria a ser fortalecida pelo próprio Roberto quando, na coleção Os Pensadores, da editora Ática, escolheu escrever sobre Mauss. Bem mais tarde, conversando com alunos da mesma UNB, descobri que o paralelo agora traçado era com Boas, formador de diferentes gerações e vertentes de antropólogos norte-americanos. Até onde pude saber, as preferências de gerações se alternaram entre Mauss e Boas.

O que motivaria os iniciantes na disciplina para essa continuada busca de um contraponto para os nossos mestres na história da antropologia? Fico com a tentação de avançar uma hipótese. Talvez este fosse um recurso ingênuo e de alguma forma divertido através do qual os que ingressavam no grupo (bem pequeno) dos antropólogos conseguiam reconhecer-se e reconhecer os seus próprios professores nos terrenos intelectuais que atravessavam, conectando o universo dos livros (e a galeria de autores já tornados "clássicos") com o das práticas acadêmicas vivenciadas nas instituições brasileiras (aulas, orientações, discussões de pesquisa). Menos que um "jeux d'esprit", que reiteradamente produziam jovens antropólogos de diferentes turmas, sem conexões diretas uns com os outros, isto se me afigura como uma espécie de nascente rito acadêmico, não um ritual de rebelião (como os descritos por Gluckman), mas um anti-ritual de ordenamento e mapeamento de iniciados diante do universo da antropologia.

Mas por que essa analogia era sempre repetida com Roberto e não com outros professores? A escolha não deixava de ser paradoxal, pois Roberto não era o mais velho da sua geração, nem estava muito distante em termos de idade dos seus discípulos mais próximos. Também não era o antropólogo mais lido e emblemático de um público maior (como Darci Ribeiro, por exemplo). Por que a busca de parâmetros para uma carreira acadêmica que 
então se iniciava no Brasil era melhor atendida pela permanente postura de scholar de Roberto? Seria uma refração da atitude de deferência e respeito em relação a ele por parte dos demais professores, eles mesmos ex-alunos e colaboradores de Roberto? Não sei, limito-me a relatar essa curiosa analogia, que nunca ouvi aplicada a outros antropólogos brasileiros.

Entre os alunos daquelas turmas com quem convivi, Roberto era visto como um professor muito bom, mas rigoroso, e que tinha elevadas expectativas quanto aos trabalhos que viriam a ser produzidos pelos seus estudantes. Lembro-me da agonia de muitos, ao retornarem de seus respectivos campos, para conseguir encontrar em seus extensos registros etnográficos algo que constituísse uma "relevância teórica" (expressão dramaticamente repetida) que pudesse ser aceita por Roberto. De uma feita, ele se recusou a aprovar uma dissertação que, na sua primeira versão, consistia na aplicação de um método formal e sofisticado de análise. Sem qualquer hesitação, argumentou que um trabalho de conclusão de um pós-graduado deveria conter uma contribuição original ou um exercício crítico. Tratava-se de um excelente aluno que logo compreendeu, e aproveitou muito bem a cobrança de Roberto como um estímulo ao amadurecimento de seu trabalho. A própria dinâmica de seus seminários, discutindo e valorizando uma bibliografia ampla, mas conduzindo a tentativas de sínteses e de novas hipóteses, já expressava bem esse movimento intelectual que era próprio de Roberto, estimulando assim a busca na direção de uma contribuição pessoal que via como indissociável do exercício de uma verdadeira autoria.

A atitude de respeito não implicava, porém, distanciamento ou formalidade. Ao contrário, era muito querido por seus alunos, a quem acolhia sempre com simpatia e cordialidade. Raramente era chamado de professor, favorecendo o tratamento direto e pelo primeiro nome. A comunidade dos antropólogos era bastante pequena e densa em relacionamentos, todos se conheciam e acompanhavam mutuamente as carreiras e as vidas como se fosse uma família cujos membros de tempos em tempos se reunissem. Assim é que os congressos da ABA vieram a ser chamados de "reunião" (brasileira de antropologia), para distinguir esse pequeno grupo fraterno e solidário de associações profissionais que realizavam grandes congressos. De acordo com esse espírito, Roberto colocava-se na condição de alguém que introduz seus alunos nessa comunidade, estimulando-os a se inserirem naquelas redes e a integrarem uma comunidade muito especial, a dos que tem a antropologia como paixão e orientação de vida.

Mais uma vez, utilizo-me de um depoimento pessoal. Durante uma dessas reuniões da ABA, em Salvador, eu estava sentado no Hotel do Carmo, bebendo e conversando com amigos, quando passou Roberto com mais 
algumas pessoas e sentou-se a uma mesa. Aos poucos fui distinguindo: lá estavam Eduardo Galvão, Egon Schaden e Luiz de Castro Faria, entre outros mais jovens, como Roque e Otávio. Comentei com meus amigos, em tom reverente, que ali se encontrava "la crème de la crème" da antropologia brasileira, ao que retrucaram dizendo que o grupo parecia bastante animado e nada similar ao clima que na época se esperava de intelectuais. Eu duvidei daquela avaliação profana e fiquei me perguntando intimamente o que estariam discutindo figuras tão destacadas. De que assuntos riam com tanta espontaneidade os antropólogos?

Logo Roberto me viu e chamou, fazendo as apresentações e falando da minha pesquisa (eu tinha recém-retornado de trabalho de campo com os Ticuna). Mandou-me puxar uma cadeira e juntar-me à mesa. Para minha surpresa, a conversa parecia a de uma reunião de família: contavam-se casos pitorescos de trabalhos de campo ou de congressos; falava-se de livros, pessoas e instituições; lembrava-se com carinho dos ausentes (inclusive alguns muito próximos, como Wagley e David). O clima era de cordialidade e, melhor diria, de fraternidade, como num encontro de velhos amigos que moravam distantes e aproveitavam a ocasião para se reabastecerem mutuamente de informações, esperanças, confidências e, sobretudo, de causos muito engraçados. Era o acesso a esses episódios (importantes ou jocosos, mas sempre memoráveis), sobre os quais os livros que escreveram obviamente nada falavam, e que no caminho inverso das biografias ou das autorepresentações compunham uma rica e diversificada experiência humana, que constituía o segredo e o privilégio daquela fraternidade.

O interesse e a preocupação de Roberto com seus ex-alunos não terminavam com a conclusão de cursos ou da tese, mas acompanhavam suas trajetórias mesmo à distância. A sua curiosidade era tanto de saber o que faziam em suas carreiras (funções, projetos, distinções), quanto de conhecer os produtos de seus trabalhos. Mantinha com alguns pesquisadores um diálogo intelectual bastante vivo, sempre enviando e recebendo trabalhos novos que cada um produzia.

Em 1994, quando a editora da UNICAMP estava preparando a $4^{\mathrm{a}}$. edição de $O$ índio e o mundo dos brancos, nós nos encontramos. Ele estava muito satisfeito com o fato e ao final abraçou-me e avisou: "Estou redigindo um posfácio, onde dialogo com seu trabalho. Vou enviar-lhe e espero seus comentários". Logo recebi o texto "Posfácio 1994 - Trinta anos depois", em que ele respondia a uma interpretação crítica que eu fizera sobre a fricção interétnica em O nosso governo: Os Ticuna e o regime tutelar (1988). Mandei-lhe meus comentários e iniciamos aí uma troca de textos que se prolongou até a sua morte. Quando o livro saiu, em 1996, presenteou-me 
com um exemplar, no qual escreveu à mão, com extrema generosidade, que o dedicava ao "meu mais atento leitor". Nos anos seguintes, alguns alunos da UNB comentaram comigo que Roberto insistia para que lessem $O$ índio e o mundo dos brancos na $4^{\mathrm{a}}$. edição, tomando ciência das críticas e das reelaborações posteriores, que considerava um exemplo da "boa controvérsia", uma decorrência natural e sadia da pesquisa e da reflexão.

Em livros e artigos de grande repercussão, RCO refletiu sobre as matrizes disciplinares da antropologia e como nelas se inseria a produção brasileira (isto é, aquela feita a partir de problemáticas e situações de pesquisa propiciadas pelas instituições universitárias e científicas nacionais). Mas para ele isto nunca significou (ou poderia significar) a desvalorização dessa produção brasileira, nem muito menos o apagamento ou a desconsideração de suas importância e fecundidade para os grandes debates da disciplina.

Um rápido encontro com Roberto nos corredores de uma RBA, em Vitória (1998), procedeu de maneira iluminada a tal apreensão. Ele saíra de um debate sobre antropologias periféricas e eu, de um GT sobre relações interétnicas. Pegou-me pelo braço e contou-me o que dissera naquele contexto. Depois, para exemplificar o seu ponto de vista, perguntou-me diretamente: "Quantos autores brasileiros você, por exemplo, utiliza no seu curso no Museu Nacional sobre etnicidade?" Antes que eu tivesse tempo de responder, ele mesmo arrematou: "Em muitas linhas de investigação sucede assim: quando se fala de teoria se esquece dos autores nacionais. Para mim isso é uma manifestação clara de provincianismo". O incômodo que Roberto sentia era que, ao tentar superar a atribuição de "periférica", a antropologia que se fazia no Brasil apenas se apresentasse como mera aplicação de modelos analíticos elaborados em outros contextos, omitindo contribuições, releituras e debates que resultavam da prática da pesquisa, da escrita e da reflexão em instituições nacionais.

Os encontros com Roberto, sempre muito agradáveis, estimulavamme a pensar. Em seus trabalhos escritos ele era lógico, comedido e erudito, perseguindo atentamente um argumento preciso, dialogando com autores explicitados e reportando-se a situações etnográficas bem definidas. Nas conversas informais, ao contrário, era muito direto e incisivo, explicava com franqueza as suas opiniões sem se preocupar em justificá-las ou contextualizá-las longamente. Assim, expunha com nitidez suas predileções e seus sentimentos, o que tornava a interlocução com ele algo muito vivo e que nem sempre se harmonizava com facilidade com as leituras habituais que se fazia do autor RCO.

A última vez em que nos encontramos foi em 2005, quando Roberto participou como examinador externo de uma banca de concurso para pro- 
fessor no PPGAS, na qual atuaram como membros da casa Moacir Palmeira e eu. Roberto estava muito bem fisicamente e de excelente ânimo, fazendo comentários oportunos e inspiradores. Estando no espaço do Museu Nacional, naturalmente em muitos momentos, durante as conversas ocorridas nos almoços, eram mencionadas personagens e eventos que foram decisivos para a fundação do PPGAS. Com muito bom humor, Roberto esclarecia alguns pontos, falando com paixão daquele contexto.

A notícia da morte de Roberto causou muita tristeza e deixou uma irreparável sensação de perda. Talvez justamente por isso gerou um fato que me pareceu sui generis e que não posso deixar de conectar com aquela espécie de nascente rito acadêmico que mencionei páginas atrás. Telefonemas e e-mails se cruzavam vindos de lugares muito distantes do Brasil e também do exterior, procedendo ora de pessoas que eram muito próximas, ora de outras que há muito não se viam nem mantinham afinidades assim tão evidentes. Instituiu-se de forma espontânea uma rede de solidariedade e mútua escuta, informal mas muito intensa, totalmente distinta das manifestações protocolares que se dirigiam à família e às instituições a que Roberto pertencera. De muitos ouvi relatos carinhosos e reverentes sobre Roberto. Todos sentiam de algum modo a necessidade de, fora de seu cotidiano e de sua própria singularidade, compartilhar imagens, idéias e emoções que envolviam diretamente algumas das múltiplas dimensões que faziam com que ele fosse caracterizado por todos como o mais evidente e consensual exemplo brasileiro de um verdadeiro scholar.

Ao concluir, reitero que, através de alguns registros de memória, minha intenção aqui foi lembrar de forma bem viva a imagem de Roberto em seu cotidiano, como professor e intelectual, especialmente para as gerações mais jovens, que não chegaram a lidar de perto com ele. Tais relatos, de caráter pontual e limitado, podem servir de estímulo, acredito, para a leitura da obra de RCO, dando uma idéia de sua atualidade. Ao buscar focalizar o Roberto, e não apenas o RCO, estou de certo modo tentando reavivar aquele sentimento de pertencer a uma comunidade de intelectuais que não se vêem puramente como autores, alimentando uma continuidade nos processos de iniciação que já faz parte das expectativas dos antropólogos. 


\section{Referências bibliográficas}

ARIZPE, Lourdes. 2004. "The intellectual history of culture and development institutions". In: Vijayendra Rao e Michael Walton (orgs.), Culture and public action. Stanford: Stanford University Press.

CAPOTORTI, Francesco. 1979. Study on the rights of persons belonging to ethnic, religious and linguistic minorities. New York: United Nations.

CARDOSO DE OLIVEIRA, Roberto. 1960. O processo de assimilação dos Terena. Rio de Janeiro: Museu Nacional.

_ 1964. O índio e o mundo dos brancos. São Paulo: Difusão Européia do Livro.

COBO, Jose R. Martinez. 1986. "Study of the problem of discrimination against indigenous population". Relatório final, ONU, Centro de Direitos Humanos.

CORRÊA, Mariza. 1992. Roberto Cardoso de Oliveira. Campinas: IFCH/UNICAMP.

DAVIS, Shelton. 2004. "The mayan movement and national culture in Guatemala". In: Vijayendra Rao e Michael Walton (orgs.), Culture and public action. Stanford: Stanford University Press.

DAMATTA, Roberto. 1976. Um mundo dividido: a estrutura social dos índios Apinayé. Petrópolis: Editora Vozes.

EIDE, Asbjorn. 1991. "Possible ways and means of facilitating the peaceful and constructive solutions of problems involving minorities". Progress report to the United Nations Sub-Commission on Prevention of Discrimination and Protection of Minorities. UN Doc. E/CN.4/Sub.2/1991/43.

LARAIA, Roque de Barros. 1992. "A comunidade de origem". In: Mariza
Corrêa \& Roque de Barros Laraia (orgs.), Roberto Cardoso de Oliveira. Campinas: IFCH/UNICAMP.

LEVI-SRAUSS, Claude. 1956. "Les organizations dualistes existent-elles?". Bijdragen tot de taal-,land en Volkenkunde, Deel 112, $2^{\circ}$ Aflevering. . 1960. "On manipulated sociological models". Bijdragen tot de taal-,land en Volkenkunde, Deel 116. - 1967 [1949]. Les structures elementaires de la parenté. Paris: Mouton. MAYBURY-LEWIS, David. "The analysis of dual organizations: a methodological critique". Bijdragen tot de taal-, land en Volkenkunde, Deel 116:2-43. - 1965. Akwen savant society. Oxford: Clarendon Press. [Tradução brasileira: Livraria Francisco Alves, Rio de Janeiro, 1984].

. 1965. "Prescriptive marriage systems". Southwestern Journal of Anthropology, 21(3):207-230. - 1992. Milenium. Tribal wisdom and the modern world. Nova York: Peguin Books.

POSEY, Darrell. 1991. "Effecting international change" Cultural Survival Quarterly. pp. 29-35.

"Prohibition of discrimination", Minority Rights - Fact Sheet, n. 18, 2001.

The rights of indigenous peoples - Fact Sheet, n. 9, 1997. 